\title{
Usage of WeChat by International Students and Its Usefulness: Study Based in Wuhan University China
}

\author{
A. W. V Athukorala \\ Senior Assistant Librarian, Sri Palee Campus, University of Colombo, Sri Lanka
}

\begin{abstract}
Article Info

Volume 8, Issue 6

Page Number : 66-75

Publication Issue

November-December-2021

Article History

Accepted : 01 Nov 2021

Published : 08 Nov 2021

China has established as a significant learning hub in Asia, with a rising number of international students entering the country each year. Although WeChat is a popular social media platform among international students in China, a few studies have been conducted on how international students utilize Chinese social media. The study's objective is to investigate international students' use of WeChat and its educational value in mainland China. Data were gathered using a survey approach. Individuals studying at Wuhan University in China were chosen as the population sample. The University of Wuhan is a complete university spanning a range of specialized fields. It is one of the best universities with the particular achievement of education in china. Data collected from the office of the College of Foreign Students Education and General Administration office at Wuhan University shows that the intake of international and local students has been steadily increased in recent years. Therefore it is reasonable to select a sample for the research from Wuhan University. To determine what concern about when using social media by college students in a transnational environment, international students at Wuhan University were selected as a sample, and questionnaires were adapted to collect data. The questionnaire is designed for the international in the Wuhan University. The questionnaire is aimed to answer research objectives. Hence, the questionnaire is used as a research instrument to collect primary data. Despite the distribution of $250(\mathrm{~N})$ questionnaires to international students, only 216 (n) completed questionnaires were received from them. According to the survey, the four most appealing features to all international students are Payment facilities, mobile calling, built-in text conversion, and multi-modal messaging. Furthermore, the study found that WeChat has a lot of possibilities in academic contexts. The majority of students embraced the use of WeChat in teaching and learning to supplement classroom instruction, and they enthusiastically agreed with WeChat's social, technological, and pedagogical benefits. Finally, the paper discusses the WeChat usage behavior
\end{abstract}


of international students, as well as its implications for improving educational value and recommendations for future research.

Keywords: WeChat, International students, Wuhan University, Educational Purposes, Social Media

\section{INTRODUCTION}

The fast growth of Chinese education has resulted in a rise in the number of Chinese students enrolling in higher education. China has achieved significant improvement in the education system in recent decades, particularly in terms of increased foreign student inflow (Nzivo\&Chuanfu, 2013). The Chinese Scholarship Council (CSC) awards a variety of scholarships to international students from all around the world each year. On the other hand, the majority of overseas students enroll in Chinese institutions as self-financial students to pursue their higher education or learn the Chinese Language.

China is a sociologist nation in which the central government manages and controls everything. Due to political and censorship concerns, access to Facebook, Google, and Twitter has been restricted in China since 2009. As a result, during their transition and to maintain contacts with their peers, WeChat has become increasingly interwoven into the host society. The WeChat application has grown in popularity among Chinese citizens, with over one billion monthly active users. It has evolved into a multifunctional smartphone application that goes beyond the capabilities of its Western counterpart, What'Sapp. In this situation, WeChat has bought individuals from many cultures together in a global community. Students in Chinese universities utilize WeChat to learn about their host countries, build and maintain contacts and stay up to date on events during their intercultural adaptation.
The rapid development of social media has fundamentally reshaped the world education system. According to several researchers, social media may help students transition from high school to college by providing them with knowledge, social support, and a method to discover and interact with other students. Facebook is the most popular social networking platform among college students in the United States (Hargittai, 2007; Smith, Salaway, \& Caruso, 2009). Most university students in the world commonly use social media networks to disseminate information and to communicate among them. CNNIC. (2009) Statistical survey report on the Internet development in China mentioned that China dominates the blogosphere worldwide, with 162 million Chinese bloggers (CNNIC, 2009). Blogging in China is not only an appreciation to leaders of thought but a kind of communal activity that emphasizes the cultural desire for unity in China (Walsh, 2019). Falahaha and Rosmalab believe that, despite the discussion over the detrimental influence of social networking on productivity, certain campus components, such as students or lecturers, are utilizing these sites to share knowledge and support communication among them (Falahaha\&Rosmalab, 2012). Chinese university students are accustomed to communicating via Chinese native social media platforms such as WeChat, QQ Sina-Weibo, Renren, Youku, and others. They spend a large portion of their time on these social media platforms, which are as popular as or more popular than Western social media platforms. The present research expects to analyse these drawbacks and then filling the gaps of the social media studies.

\section{Objectives Of the study}


With a rising number of international students moving to the Wuhan University of China each year to pursue higher education, it is critical to look at domestic Social Media Networks (SNS) acceptance and usage by international students in Wuhan University. The purpose of this study is to investigate the following three goals.

OB; 01 To investigate why, and how international students in Chinese Universities use WeChat.

OB: 02 To understand the purpose use of WeChat in Chinese higher education institutes (HEIs).

OB: 03 To examine what kind of services are provided through WeChat for the international Students.

\section{Literature Review}

Most of the literature related to social media in Chinese society is emphasized that, as most Western social media sites are being restricted in China, an alternative of local social media has rapidly emerged in Chinese society (Crampton, 2011). Even though ICQ and MSN were successful in entering the Chinese market, both quickly lost ground to local competitors due to a lack of user-centered interface design adapted to local Chinese users. Despite WeChat's rapid expansion, exploration of the possible impacts of WeChat usage on individual levels is presently lacking. A variety of factors may have led to the paucity of studies in this subject. Despite the growing body of research on the effects of social media use, past research has mostly focused on the most famous social media tools in Western countries. The aforementioned findings in western nations could not easily be broadened to identify the prospective influence of WeChat on China and other high-use countries in the light of possible artistic transformations as well as the more sophisticated integrated features of WeChat. Second, WeChat is still not extensively recognized and utilized by many people residing in western nations, despite its popularity in Asia. With significant changing costs, it is not simple for them to transfer from existing social media to new media (e.g., see Wilson et al. (2012) and Montag et al. (2018) for reviews on Facebook research).

The area of early research on WeChat was to better understand the motivating components of the app. In this regard, Gan and Wang (2015) (interview research with 18 participants) and Wang et al. (2015) noted that the need for social interaction is one of the most powerful motivators for using WeChat. The findings of Mao (2014), which showed that WeChat is also utilized to relax and relieve tension among 200 students, support this viewpoint. According to the study conducted by Mao (2014), Lien and Cao (2014) identified proof that motivating variables such as amusement, sociality, and knowledge on influence WeChat attitudes. Positive word of mouth was connected to a positive attitude toward WeChat. Whereas both the variable of attitude toward WeChat and the variable of word of mouth was positively impacted by the factor trust in WeChat (Lien and Cao, 2014).

Huwa Pang (2018) has studied to investigate the nature of friendship between college students and perceived well-being. The results of the investigation have concluded that Although WeChat is one of the fastest-growing social media outlets in mainland China, several scientists and academics still need to thoroughly examine the possible social and psychological effects of the new social online network. The main objective of this study was to test and to understand whether and how the use of WeChat is connected to the quality of friendship and psychological well-being of people based on theory and prior studies. A total of 508 university students completed anonymous surveys measuring the use, self-review, quality of friendship, and wellness of their WeChat compliance participants.

\section{Methodology}


Data were gathered using a survey approach. Individuals studying at Wuhan University in China were chosen as the research population. Wuhan University is a comprehensive institution covering a whole range of disciplines with a unique feature. It is one of the best universities with the particular achievement of education in china. Data collected from the office of the College of Foreign Students Education and General Administration office at Wuhan University shows that the intake of international and local students has been steadily increased in recent years. Therefore it is reasonable to select a sample for the research from Wuhan University. International students at Wuhan University were selected as a sample and questionnaires were adapted to collect data. The questionnaire is aimed to answer research objectives. Hence, the questionnaire is used as a research instrument to collect primary data.

The questionnaire is mostly composed of structured, closed-ended, and open-ended questions, multiplechoice questions, and attitude scales to collect the information needed to meet the study's goal.
Structured close-ended kinds are employed because they are often defined by a set of predetermined replies from which respondents can pick one or more to express diverse points of view. An attitudinal scale is a tool for gathering a range of viewpoints on attitudes. Open-ended questions are designed to allow respondents to freely express their opinions. The questionnaire was broken into three sections. The first section discusses demographic characteristics such as university name, gender, age, education, nationality, student type, period of residing in China, and having a WeChat account before traveling to China. The second section discusses the features of WeChat usage and activity. The data collected were methodically entered into the SPSS package for analysis. Descriptive statistics enable the selection of frequencies, description, and cross-tabulation. It is worth mentioned here that all international (86.4\%) were highly responded and participated in the answer to the questionnaire. Despite the distribution of $250(\mathrm{~N})$ questionnaires to international students, only 216 (n) completed questionnaires were received from them.

\section{Data Analysis}

Profile Information

Table : 1 Country and languages of the sample

\begin{tabular}{|l|l|l|l|}
\hline $\begin{array}{l}\text { Country } \\
\text { Distribution }\end{array}$ & $\%$ & $\begin{array}{l}\text { Language } \\
\text { Distribution }\end{array}$ & \\
& & & $\%$ \\
\hline Asian Countries & 57.52 & French & 16.6 \\
\cline { 1 - 3 } European Countries & 25.91 & Korean & 6 \\
& & English & 13.4 \\
& Russian & 2 \\
African Countries & 16.57 & Hindi & 4.62 \\
& & Thai & 4.62 \\
& & Vietnam & 4.62 \\
& & Urdu & 5.55 \\
& & Portuguese & 6.48 \\
& & German & 4.62 \\
& & Bangla & 2.32 \\
& & Nepal & 1.85 \\
\hline
\end{tabular}




\begin{tabular}{|l|l|l|l|}
\hline & Sinhala & 4.62 \\
& & Malagasy & 2.31 \\
& Spanish & 2.77 \\
& & Kazakh & 1.85 \\
& Arabic & 4.16 \\
& Tamil & 1.85 \\
& & 1.85 \\
\hline
\end{tabular}

Table: 1 shows international students' samples according to the countries' distribution and language distribution. A complete inspection of the questionnaires of the international students shows that $57.52 \%$ of the students were from Asian countries while $25.91 \%$ were from European countries. These distributions of various language categories show that Wuhan University consists of a multicultural community from different parts of the world. Greenberg and Ilan argue that students from different native language groups from various cultures and backgrounds seek information, the differences in their information behavior and their differences in overcoming language barrier[s] (Greenberg and Ilan, 2013).

Table 2 : Sample Distributed by the Demographic statistics

\begin{tabular}{|c|c|c|c|c|c|}
\hline Measure & $\mathrm{N}$ & n (\%) & Measure & $\mathrm{n}$ & $\begin{array}{c}\mathrm{n} \\
(\%)\end{array}$ \\
\hline \multicolumn{3}{|c|}{ Gender } & \multicolumn{3}{|c|}{ Types of Students } \\
\hline \multirow[t]{3}{*}{ Male } & \multirow[t]{3}{*}{153} & \multirow[t]{3}{*}{81.7} & \multirow[t]{3}{*}{ Scholarship } & 1 & 77.3 \\
\hline & & & & 6 & 1 \\
\hline & & & & 7 & \\
\hline \multirow[t]{2}{*}{ Female } & \multirow[t]{2}{*}{63} & \multirow[t]{2}{*}{18.3} & \multirow[t]{2}{*}{ Self-Funded } & 4 & 22.6 \\
\hline & & & & 9 & 8 \\
\hline \multicolumn{3}{|c|}{ Age } & \multicolumn{3}{|c|}{ How long have you been in China? } \\
\hline \multirow[t]{2}{*}{ Under 20} & \multirow[t]{2}{*}{08} & \multirow[t]{2}{*}{3.7} & Less than one & 9 & 42.5 \\
\hline & & & year & 2 & 9 \\
\hline \multirow[t]{2}{*}{$20-25$} & \multirow[t]{2}{*}{67} & \multirow[t]{2}{*}{31.01} & \multirow[t]{2}{*}{$1-2$ years } & 5 & 26.3 \\
\hline & & & & 7 & 8 \\
\hline \multirow[t]{2}{*}{$26-30$} & \multirow[t]{2}{*}{43} & \multirow[t]{2}{*}{19.9} & \multirow[t]{2}{*}{$3-4$ years } & 4 & 21.7 \\
\hline & & & & 7 & 6 \\
\hline \multirow[t]{2}{*}{$31-35$} & \multirow[t]{2}{*}{52} & \multirow[t]{2}{*}{24.07} & \multirow[t]{2}{*}{$5-6$ years } & 1 & 5.09 \\
\hline & & & & 1 & \\
\hline \multirow[t]{2}{*}{ Above 35} & \multirow[t]{2}{*}{46} & \multirow[t]{2}{*}{21.29} & 7 and Above & 0 & 4.18 \\
\hline & & & years) & 9 & \\
\hline \multicolumn{3}{|c|}{ Education } & & & \\
\hline Ph.D. & 46 & 21.3 & \multirow{2}{*}{\multicolumn{3}{|c|}{ Before coming to China, do you have }} \\
\hline Master's & 57 & 26.3 & & & \\
\hline
\end{tabular}


A. W. V Athukorala Int J Sci Res Sci \& Technol. November-December-2021, 8 (6) : 66-75

\begin{tabular}{|l|l|l|l|l|c|}
\hline & & & \multicolumn{3}{|c|}{ a WeChat account? } \\
\hline $\begin{array}{c}\text { Bachelor and } \\
\text { non-degree }\end{array}$ & 113 & 52.4 & Yes & 2 & 11.1 \\
& & & & 4 & 2 \\
\hline & & & No & 1 & 88.8 \\
& & & & 2 & 8 \\
\hline & & & & & \\
\hline
\end{tabular}

According to Table: 1 data were collected through the question on the topic of how long they had been in China, the majority of respondents (42.59\%) said they had been there for less than years, $26.38 \%$ for less than 1 to 2 years, 21.76\% for 3 to 4 years, and 5.09\% 5 to 6 years. In response to whether they used WeChat before coming to China, the majority of the students in sample 192 (n) (88.88\%) said they did not have a WeChat account before coming to China, while $11.12 \%(24=n)$ said they did not have.

Figure: 1 International student experience in WeChat Usage-In years

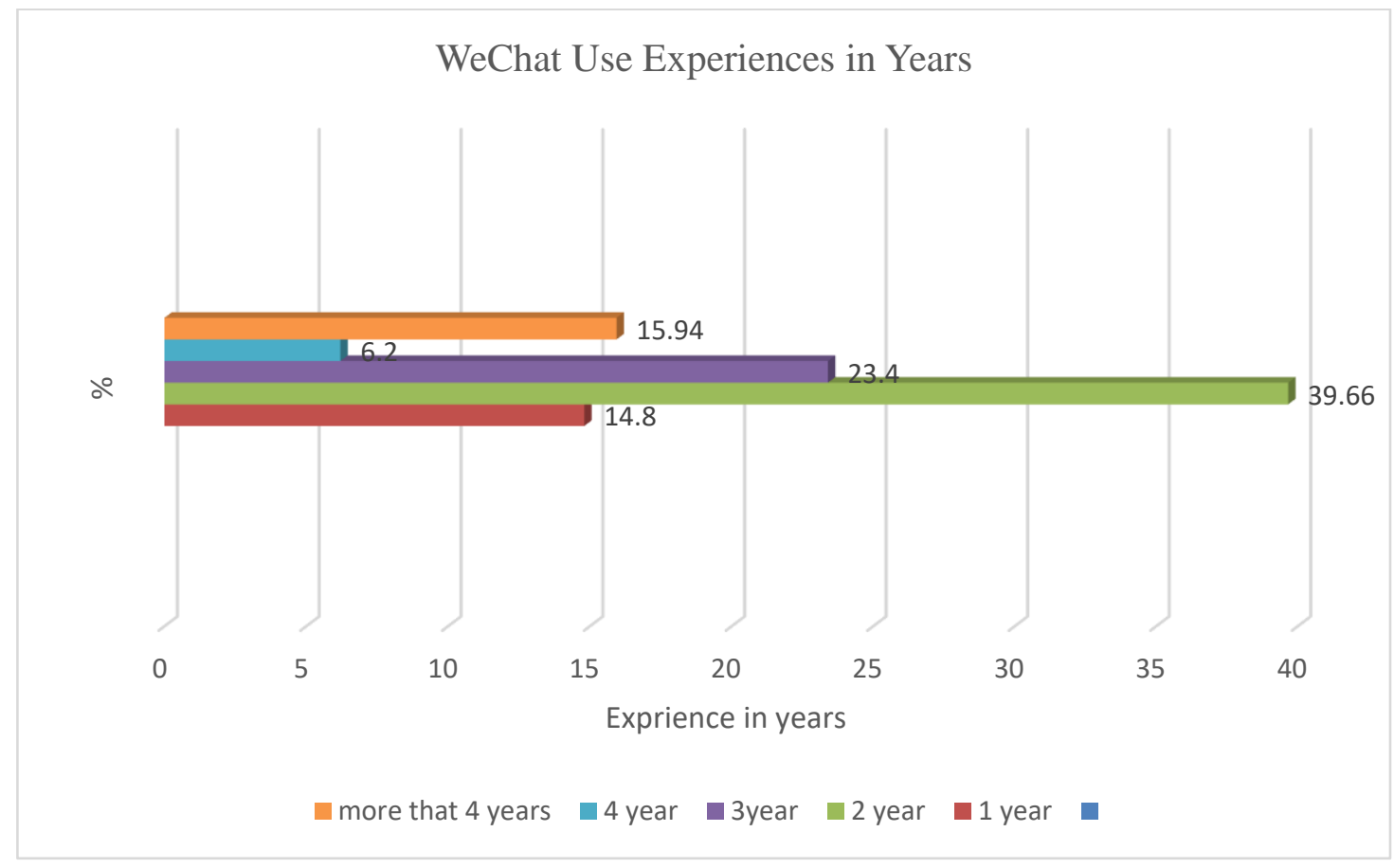

As to questions regarding the use of the WeChat by foreign students in the years, shows Figure: 1. a large number of WeChat students (39.66\%) for two years, $23.4 \%$ for three years and $15.94 \%$ more than four years and less number of students for 4 years in experiencing. That is 6.2 of the total sample studied. 
A. W. V Athukorala Int J Sci Res Sci \& Technol. November-December-2021, 8 (6) : 66-75

Figure: 2 Purpose for use WeChat

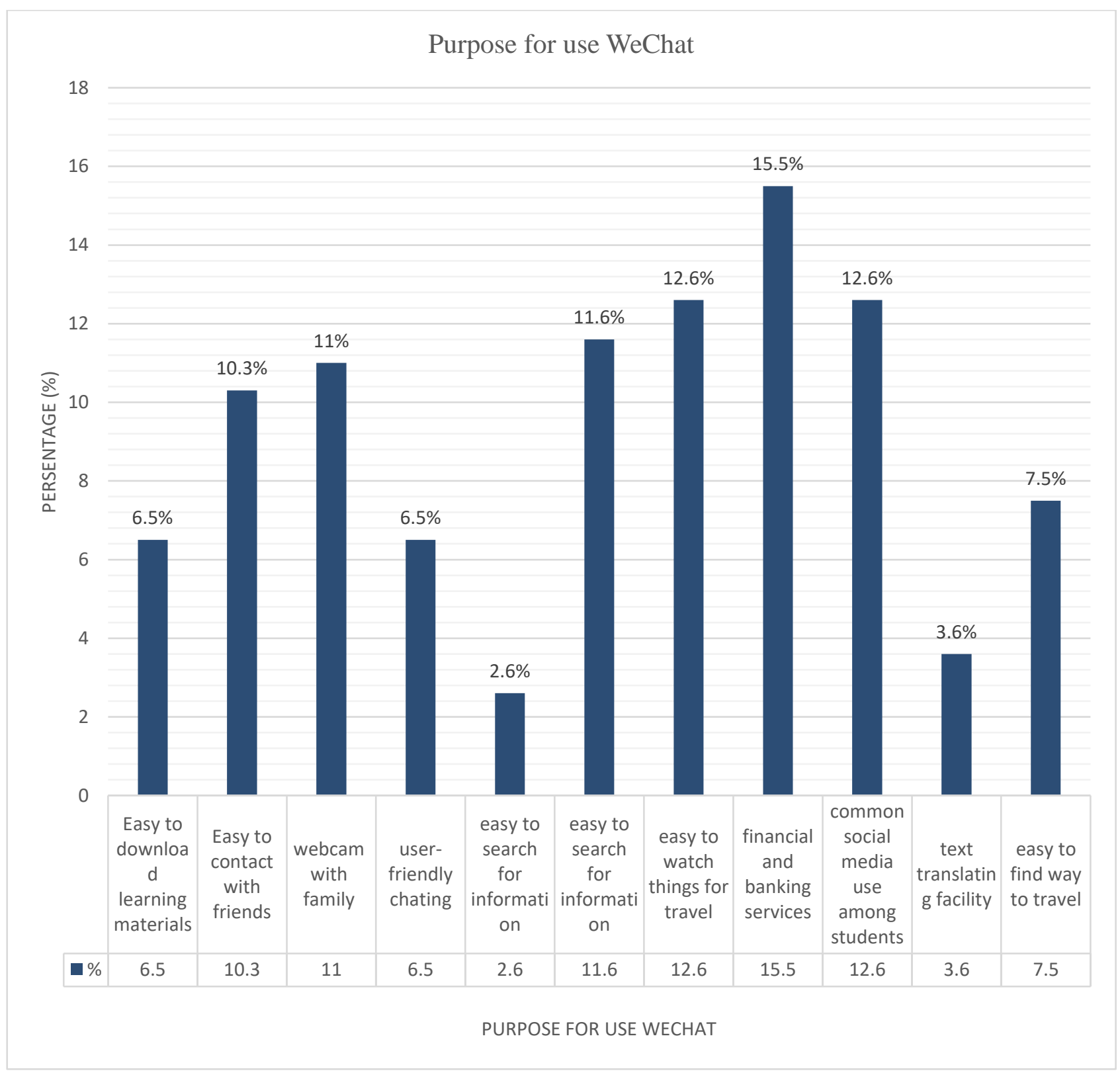

One of the objectives of the study was to figure out why international students use WeChat and how to adapt them to Chinese culture. Figure 2 depicts the findings. According to the graph, international students at Wuhan University in China utilize WeChat for a variety of reasons. The majority of respondents said they had used WeChat in China for banking and financial activities (15.5\%). Furthermore, a significant number of international students in the sample (12.6\%) were compelled to use WeChat because it is a popular social media platform among university students and allows them to keep track of things while traveling. 
A. W. V Athukorala Int J Sci Res Sci \& Technol. November-December-2021, 8 (6) : 66-75

Figure: 3 International Students Usage of WeChat and other Social media Platforms

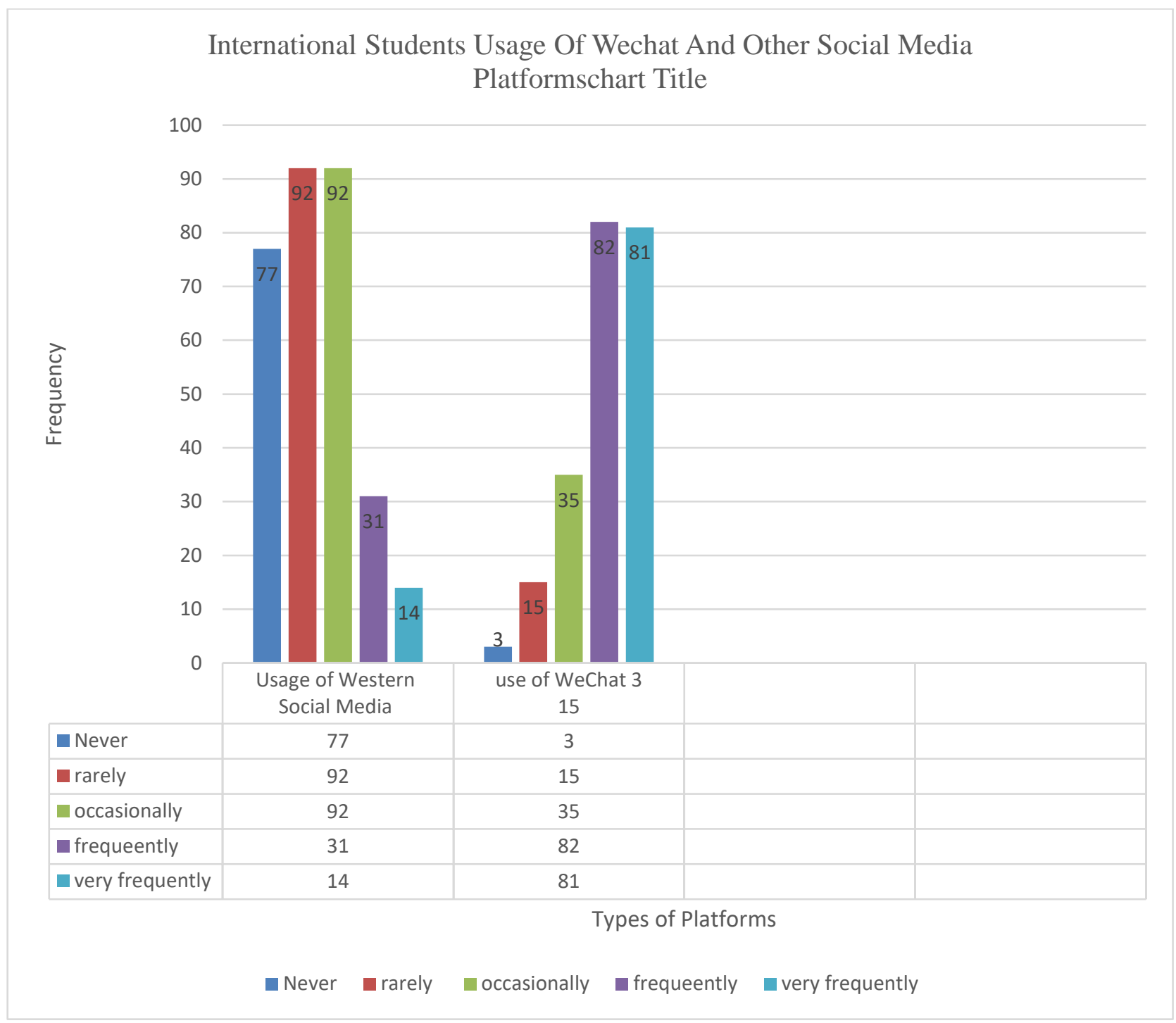

When compared to WeChat, the study sought to determine how and to what extent international students utilize other social media. Figure: 3 provides the information gathered for this purpose. When compared to other social media sites, the majority of foreign students choose WeChat. While 82\% use WeChat Frequently, and 31\% use other social media frequently. Most of the international students use WeChat (81\%) and $14 \%$ of them very frequently use other social media platforms. 
A. W. V Athukorala Int J Sci Res Sci \& Technol. November-December-2021, 8 (6) : 66-75

Table: 3 Usage of WeChat for Educational Purposes

\begin{tabular}{|l|l|l|}
\hline Educational usefulness & $\begin{array}{l}\text { Number of } \\
\text { Students }\end{array}$ & $\%$ \\
\hline WeChat group help to solve subject-related issues and questions & 184 & 85.18 \\
\hline $\begin{array}{l}\text { Teaching staff support to solve subject-related issues through } \\
\text { WeChat groups. }\end{array}$ & 198 & 91.66 \\
\hline $\begin{array}{l}\text { The teaching staff uses WeChat to inform student's assignments } \\
\text { deadlines and other information. }\end{array}$ & 187 & 86.57 \\
\hline A great way for teaching staff to communicate with students & 189 & 87.5 \\
\hline $\begin{array}{l}\text { "WeChat' "searching" facility extremely help to find academic } \\
\text { resources. }\end{array}$ & 210 & 97.22 \\
\hline WeChat can be easily used for academic file transfer & 196 & 90.74 \\
\hline Reading and sharing are very much easy & 158 & 73.14 \\
\hline
\end{tabular}

The chart demonstrates that international students use WeChat for a variety of educational objectives. The majority of students in the samples $(97.22 \%, \mathrm{n}=210)$ use WeChat for "searching," which is highly helpful in finding academic materials. The second-highest number of students using Wechat for help from teaching personnel in resolving subject-related difficulties via WeChat groups $(91.66 \%, \mathrm{n}-198)$. In addition, the data reveals that $90.74 \%$ of students utilize WeChat to communicate with one another on academic matters. The least number of students in the sample (73.14\%) has stated that Reading and sharing are very much easy via WeChat.

\section{Conclusion}

Finally, the movement of international students and their acculturation into their new environment has piqued worldwide interest. Many previous studies on the phenomena of foreign students have been done in a variety of locations, but a comprehensive study on Chinese inbound international students' usage of social media in mainland China is still lacking. The study used quantitative research to identify a gap in current information about incoming Chinese foreign students' domestic social media adoption and usage behavior in mainland China.
As a result, the study's findings have substantial and practical implications for educational program makers and academic institutions such as colleges and universities that employ WeChat as an educational tool. The study's findings will provide crucial insight into the usage of social media by prospective foreign students and other travelers in China, such as employers, investors, and visitors.

According to the survey, the majority of respondents use WeChat for everyday connection with their families, sending messages to friends, and receiving information about their education. There are many more features accessible on WeChat that might be useful to students, such as shopping, banking, and ordering a cab, to name a few. Except for foreign students who have been in China for a longer period, most international students are unaware of these functions. The study found that using WeChat wastes a lot of time and money, even on things that aren't required, and that it has several negative consequences for students' lives since too much time spent on these media is unhealthy, both physically and mentally. Despite China's internet censorship policies, the majority of overseas students use western social media platforms such as Facebook and Twitter, with the bulk of them gaining access to these platforms through the 
use of an illicit app such as Siphon. It is tough for them to change their behavior because it is the most reliable and cost-effective way of interacting with their friends and relatives back home. Furthermore, WeChat is assisting international students in attaining their educational goals in a variety of ways. As a result, the study concludes that WeChat may be used as an educational tool for overseas students studying at Chinese institutions.

The study suggests several research options for future studies to consider. To begin, a longitudinal study strategy is suggested. This will aid instructors in better comprehending the changes in foreign students' SNS usage behavior and educational value in mainland China. Second, it is suggested that qualitative and quantitative methods be combined. In this case, an indepth interview with respondents is more beneficial in terms of partially validating the survey results. Finally, cluster analysis would aid in gaining a better understanding of different groups of international students' SNS usage and behavioral measures in China.

\section{REFERENCES}

[1]. Crampton, T. (2011). Social media in China: The same, but different. China Business Review. JanuaryMarch,2011. Retrieved on June. 08, 2021, https://www.chinabusinessreview.com/social-mediain-china-the-same-but-different/

[2]. Nazivor. C \& Chuanfu. C. (2013).International Students' Perception of Library Services and Information Resources in Chinese Academic Libraries, The Journal of Academic Librarianship 39(2):129-137, March 2013 DOI: 10.1016/j.acalib.2012.11.004
[3]. Hargittai, E. (2007). Whose space? Differences among users and non-users of social network sites. Journal of Computer-Mediated Communication, 13(1), article 14. http://jcmc.indiana.edu/vol13/issue1/hargittai.ht ml

[4]. Smith, S., Salaway, S., \& Caruso, J. B. (2009). The ECAR study of undergraduate students and information technology. Retrieved from http://www.educause.edu/ecar

[5]. Walsh, JP, O'Connor, C (2019) Social media and policing: A review of recent research. Sociology Compass 13(1).

[6]. Falahah, and Rosmala.D (2012).Study on social networking usage in higher education environment, the 3rd international conference on e-learning, ICEL (2011)23-24 November. Available at www.sciencedirect.com

[7]. Wilson, R. E., Gosling, S. D., and Graham, L. T. (2012). A review of Facebook research in the social sciences. Perspect. Psychol. Sci. 7, 203-220. doi: 10.1177/1745691612442904

[8]. Montag, C., Zhao, Z., Sindermann, C., Xu, L., Fu, M., $\mathrm{Li}$, J., et al. (2018). Internet Communication Disorder and the structure of the human brain: initial insights on WeChat addiction. Sci. Rep. 8:2155. doi: 10.1038/s41598-018-19904-y

[9]. Gan, C., and Wang, W. (2015). Uses and gratifications of social media: a comparison of microblog and WeChat. J. Syst. Inform. Technol. 17, 351-363. doi: 10.1108/JSIT-06-2015-0052

[10]. Mao, C. (2014). Friends and relaxation: key factors of undergraduate students' WeChat using. Creat. Educ. 5, 636-640. doi: 10.4236/ce.2014.58075

[11]. Lien, C. H., Cao, Y., and Zhou, X. (2017). Service quality, satisfaction, stickiness, and usage intentions: an exploratory evaluation in the context of WeChat services. Comput. Hum. Behav. 68, 403-410. doi: 10.1016/j.chb.2016.11.061

\section{Cite this article as :}

Sh A. W. V Athukorala, "Usage of WeChat by International Students and Its Usefulness: Study Based in Wuhan University China", International Journal of Scientific Research in Science and Technology (IJSRST), Online ISSN : 2395-602X, Print ISSN : 2395-6011, Volume 8 Issue 6, pp. 66-75, November-December 2021. Available at doi : https://doi.org/10.32628/IJSRST218585 Journal URL : https://ijsrst.com/IJSRST218585 